\title{
REVISITANDO O DESMAME PRECOCE ATRAVÉs de RECORTES dA HISTÓRIA ${ }^{1}$
}

Sueli Mutsumi Tsukuda Ichisato ${ }^{2}$ Antonieta Keiko Kakuda Shimo ${ }^{3}$

Ichisato SMT, Shimo AKK. Revisitando o desmame precoce através de recortes da história. Rev Latino-am Enfermagem 2002 julho-agosto; 10(4):578-85.

A ação básica de saúde requer estratégia direcionada quanto à tomada de consciência da importância do aleitamento materno, principalmente para redução da morbi-mortalidade infantil. A história da amamentação mostra um hiato sobre como os povos lidaram com o desmame precoce. Objetiva-se, neste estudo, revisitar o desmame precoce através de recortes históricos. A revisão bibliográfica foi a estratégia utilizada para este estudo. A amostra constou de livros, monografias, teses, dissertações, textos publicados em revistas científicas e artigos captados via Internet, no período de 1978 a 1998, os quais retratam histórias desde a época mitológica até os séculos atuais. A revisão apontou que o desmame é sócio-culturalmente construído e determinado e que a mulher, para manter o aleitamento materno, necessita não só de suporte/apoio familiar e social, mas também governamental.

DESCRITORES: desmame, aleitamento materno, amamentação, lactação

\section{REVISITING EARLY WEANING THROUGH HISTORICAL ANALYSIS}

Basic health actions require strategies towards awareness development concerning the importance of breastfeeding, particuarly aiming at the reduction of child morbi-mortality The history of breastfeeding presents a gap of information about how people have dealt with early weanin. This study aimed at revisiting early weaning the historical analysis of breastfeeding. The literture review methodology was used. The samples consisted of books, monographs, theses, dissertations, texts published in scientific journals and scientific articles obtained through the internet in the period of 1978 to 1998. These sources portray stories from mythological times up to this day. The review pointed out that weaning is socially and culturally constructed and determined and that, in order to maintain breastfeeding, women require not only social and family support, but also governmental support.

DESCRIPTORS: weaning, breastfeeding, lactation

\section{ReVisando el destete precoz a través de recortes de la historia}

La acción básica de salud requiere estrategias dirigidas hacia la toma de conciencia de la importancia del amamantamiento materno principalmente para la disminución de la morbi-mortalidad infantil. La historia del amamantamiento muestra un vacío acerca de cómo los pueblos lidiaron con el destete precoz. El presente estudio pretende revisar el destete precoz a través de recortes históricos. La revisión bibliográfica fue la estrategia utilizada para el estudio. La muestra estuvo compuesta por libros, monografías, tesis, disertaciones, textos publicados en las revistas científicas capturados a través de Internet en el periodo de 1978 a 1998, los cuales retratan la historia desde la época mitológica hasta los siglos más actuales. La revisión mostró que el destete es socialmente construido y determinado y que la mujer para mantener la lactancia materna necesita no solo de soporte familiar y social si no también del apoyo gubernamental.

DESCRIPTORES: destete, amamantamiento materno, amamantar

\footnotetext{
${ }^{1}$ Trabalho apresentado no $2^{\circ}$ Encontro de Enfermagem Neonatologia, na cidade de São Paulo, em $1998 ;{ }^{2}$ Enfermeira, Doutoranda da Escola de Enfermagem de Ribeirão Preto, da Universidade de São Paulo, Docente da disciplina Assistência de Enfermagem em Situações Clínicas II (Enfermagem Pediátrica) do Curso de Graduação em Enfermagem do Centro Universitário Barão de Mauá (Ribeirão Preto), e-mail: sichisato@hotmail.com; ${ }^{3}$ Enfermeira, Professor Doutor do Departamento de Enfermagem da Faculdade de Ciências Médicas da Universidade Estadual de Campinas, Docente aposentada da Escola de Enfermagem de Ribeirão Preto, da Universidade de São Paulo, Centro Colaborador da OMS para o desenvolvimento da pesquisa em enfermagem, e-mail: akkshimo@terra.com.br
} 


\section{INTRODUÇÃO}

Durante os primeiros seis meses de vida, talvez seja necessário preconizar o aleitamento materno exclusivo no Brasil, para que muitas mães adquiram confiança na sua própria capacidade de amamentar.

Pertencemos à Classe Mammalia, e a nossa principal característica é a total dependência alimentar que os recém-nascidos têm de suas mães, sendo que onde o aleitamento é sinônimo de sobrevivência, portanto, um direito inato ${ }^{(1)}$.

Além de ser o mais completo alimento para o bebê, o leite materno atua como agente imunizador, acalenta a criança no aspecto psicológico, tem a vantagem técnica por ser operacionalmente simples, é de baixo custo financeiro, protege a mulher contra câncer mamário e ovariano, auxilia na involução uterina, retarda a volta da fertilidade e otimiza a mulher em seu papel de mãe $e^{(2)}$. Alertamos para que não se associe redução de câncer mamário com o fato de a mulher ter amamentado.

Inseridas num contexto que exige, por parte dos profissionais da área de saúde, o descobrir e o assumir a responsabilidade de ser elemento de transformação, sentimos que se fazem necessárias mudanças enriquecidas com orientações, incentivos, gestos de apoio e carinho, deixando de lado a visão romântica do aleitamento materno, enfatizado, muitas vezes, como um ato de amor, pois, mesmo não amamentando ao seio, a mãe é capaz de desenvolver o amor materno. "O amor ou não amor transcende, em muito, o ato do aleitamento. Para amamentar uma criança não é necessário que se a ama, como também, para amar uma criança, não é necessário amamentá-la"(3).

Entretanto, muitas vezes, por questões culturais, o fato de a mulher não ter amamentado faz com que a denominem mãe desnaturada, o que aumenta, em demasia, o sentimento de culpa da mulher.

A ação básica de saúde requer estratégia direcionada quanto à tomada de consciência da importância do aleitamento materno. Vivemos em um país em desenvolvimento, com alto índice de mortalidade infantil, muitas vezes causada pela alimentação inadequada na primeira infância, acarretando desnutrição, baixa resistência orgânica e, conseqüentemente, quadros infecciosos irreversíveis, aos quais o não aleitamento materno é apontado como uma das causas.

É importante não associar a falta do leite humano com a questão da desnutrição infantil, pois o não acesso a outras fontes alimentares e alternativas é que promovem a desnutrição nas crianças ${ }^{(3)}$.

Várias campanhas foram veiculadas pela mídia escrita e falada devido ao desmame precoce, porém isso tem surtido pouco efeito na promoção do aleitamento materno. No V Encontro Nacional do Aleitamento Materno foi apresentada uma exposição histórica de inúmeros pôsteres, em seus tamanhos originais e de vários países. $\mathrm{E}$, após várias análises feitas, concluiu-se que, para uma promoção eficaz do aleitamento materno, é necessário um trabalho interdisciplinar entre os profissionais de marketing e consultores de amamentação ${ }^{(4)}$.

Apesar de grande interesse demonstrado nos últimos anos, aparece um hiato nessa história: o desmame precoce. Como os povos lidaram com isso? Era considerado natural? O objetivo do estudo é revisitar o desmame precoce por meio de recortes históricos do aleitamento materno.

\section{METODOLOGIA}

A revisão bibliográfica foi a estratégia utilizada para este estudo. A amostra constou de textos, publicados no período de 1978 a 1998, que retratam a história da amamentação desde a época mitológica até o século XX.

A busca foi realizada em livros, artigos de revistas científicas, monografias, dissertações de mestrado, teses e artigos extraídos via Internet, buscados nos bancos de dados da MEDLINE e LILACS.

Foram incluídos para análise textos que contivessem dados históricos, sociais e culturais relacionados ao aleitamento materno, independente da origem ou da profissão dos autores, pois interessavanos como os povos lidaram com a questão do desmame precoce.

Encontramos vinte artigos ${ }^{(1,4-5,9,11-25)}$. Após a leitura exaustiva dos textos, eles foram categorizados em cinco temas.

\section{ANÁLISE DOS DADOS}

Conseqüências do desmame precoce para o bebê

O valor do aleitamento materno na proteção da 
criança contra as infecções, pela existência de fatores específicos e inespecíficos, é bastante conhecido ${ }^{(5)}$, assim como a atuação do colostro sobre a mucosa intestinal, que auxilia na maturação dos enterócitos, melhora a absorção dos nutrientes e forma barreira de proteção contra as infecções ${ }^{(5-11)}$.

O desmame precoce é prejudicial à mãe e ao bebê, exercendo um papel de seleção natural. A mãe perde a proteção natural contra a contracepção e o câncer da mama e do ovário. A criança, por sua vez, a proteção contra as gastroenterites e infecções respiratórias ${ }^{(1)}$.

Percebemos, em nosso cotidiano, que crianças desmamadas precocemente apresentam maior índice de internação hospitalar por infecções respiratórias, gastrointestinais e não comumente a alergia ao leite de vaca, incluindo, ainda, sensibilização a outros alimentos (soja, milho, feijão, tomate, laranja, ovo, etc.).

O substituto do leite materno

Em resgate histórico realizado, verificou-se que, desde tempos remotos, a civilização humana tem interferido na amamentação. No início, substituindo o seio materno, devido a capricho/fragilidade da nutriz, e posteriormente, pela comodidade das mulheres ${ }^{(1,12-16)}$.

Os diferentes tipos de mamadeiras já eram conhecidos na Grécia e na Itália, no ano 4.000 a.C., e, no ano de 888 a.C., já havia sinais de uso de mamadeiras em desenhos feitos nas ruínas de Ninevah, no Egito ${ }^{(15)}$.

A mitologia Grega conta a história de Rômulo e Remo que foram amamentados por uma loba, e Zeus, por uma cabra. Já os egípcios, babilônios e hebreus tinham como tradição amamentarem seus filhos por três anos, enquanto as escravas eram alugadas por Gregos e Romanos ricos, como amas de leite ${ }^{(1)}$.

Plutarco e Tácito eram romanos filósofos e moralistas que condenavam o aleitamento exercido pelas amas de leite, pois acreditavam que o vínculo entre a criança e a ama de leite prejudicava a relação entre a criança e a mãe natural, fato descrito historicamente ${ }^{(13)}$, pois as amas de leite apegavam-se ao bebê, já que a ele era dado o seu leite e o seu carinho. Havia o sofrimento da criança e da ama de leite, quando expirava o período estipulado. Atualmente, essa prática é condenada, devido à passagem do vírus do HIV da mãe para o bebê por meio do aleitamento materno, doença altamente contagiosa cuja cura ainda não se encontrou ${ }^{(5)}$.
O costume e a higienização da amamentação

No século XVIII, Dr. Willian Cadogan, um médico inglês, publicou um panfleto denominado: 'Ensaio sobre a amamentação e o manejo de crianças do nascimento aos 3 anos', que foi traduzido e reimpresso na Inglaterra, França e América ${ }^{(1)}$.

Nesse panfleto, o médico fixou horários, quatro mamadas, com intervalos regulares durante 24 horas, e proibia mamadas noturnas, contribuindo para que esses horários fossem adotados como regras ${ }^{(1)}$.

Concordamos em partes com esse médico quanto à necessidade da disciplina do horário, porém, pela anatomofisiologia do recém-nascido reduzir o número de mamadas torna-se uma atitude incorreta, pois sabemos a debilidade que isso provoca na criança em termos nutricionais.

O fato de o ser humano atualmente dormir em camas elevadas pode contribuir para o desmame precoce. Conta-se que, nas sociedades caçadoras tradicionais, o bebê dormia ao lado da mãe no chão, a criança mamava sempre que tinha fome, e a amamentação não era prejudicada durante toda a noite. Com a evolução do tempo, o ser humano começou a dormir em camas elevadas, e o bebê foi colocado em um berço no mesmo quarto, pois a mãe temia a queda da criança da cama do casal. O bebê começou a chorar quando tinha fome, acordando os pais. Com isso, o bebê foi banido também do quarto dos pais, passando a ter o seu próprio quarto, necessitando de babás e outros suportes, como chupetas e carrinhos ${ }^{(1)}$.

Não podemos atribuir o desmame precoce à questão da cama elevada ou mesmo a quartos separados, mas aos aspectos socioculturais em que a prática da amamentação deixou de ser vista como uma imagem rotineira, e também às atribulações da vida moderna, com a participação mais ativa da mulher no grupo social.

$\mathrm{Na}$ sociedade atual, dependendo das condições de vida do casal, apesar de a gravidez não planejada ter surgido de um ato amoroso, a criança pode ser vista como um fardo, como algo descartável ou desprezível, como nos séculos passados ${ }^{(17)}$.

\section{A amamentação no Brasil e na Europa}

Foi realizado, em $1990^{(16)}$, um resgate histórico- 
social quanto aos saberes e práticas sobre aleitamento materno na sociedade brasileira. Notou-se que, nos séculos XVI e XVII, o hábito do aleitamento materno entre os índios Tupinambás, que habitavam diferentes pontos do litoral brasileiro, não havia sofrido influência européia.

A sociedade Tupinambá administrava de forma harmoniosa o duplo papel da mulher como nutriz e trabalhadora. Essa mulher carregava o seu bebê 24 horas por dia atado ao seu corpo, praticando a amamentação sob livre demanda. Com a vinda dos europeus a terras brasileiras, muitos dos hábitos indígenas sofreram mudanças, inclusive o aleitamento materno ${ }^{(16)}$.

$\mathrm{Na}$ Europa, a França ${ }^{(13)}$ foi considerada o primeiro país a confiar os filhos a amas de leite. Por isso foi realizado um resgate histórico com o intuído de compreender a atitude das mulheres frente ao desmame. Após esse levantamento, salientou-se a importância de se ver a mulher como uma figura tridimensional, além de mãe e esposa, visualizar a sua individualidade como mulher, com todas as aspirações que são seu direito, para daí se perceber a sua atitude frente aos comportamentos maternos.

Desde o surgimento da civilização ocidental, a mulher e a criança eram consideradas como seres inferiores, e os homens, a imagem de Deus. Tinham como suporte a teologia cristã que reafirmava a posição de um ser perfeito com pátrio poder, com direito à vida ou à morte sobre os seus familiares. Cabia à mulher a modéstia e manter-se calada ${ }^{(13)}$.

As crianças, antes de 1760 (início do século XVII), eram consideradas como "símbolo da força do mal, um ser imperfeito, esmagado pelo peso do pecado original". Não obstante, eram tidas como um estorvo. Dessa forma, explica-se o abandono, infanticídio, a indiferença, a contratação de amas de leite para substituir o seio materno, denotando-se rejeição ao filho ${ }^{(13)}$.

Os teólogos viam a amamentação como "relação amorosa e física entre a mãe e o filho, a fonte de má educação" ${ }^{\text {(13). }}$.

A primeira agência de amas na França surgiu no século XIII e que era utilizada por mulheres da aristocracia. O intervalo até o século XVIII foi pouco documentado, porém por meio de diários particulares, sabe-se que, no século XVI, as mulheres amamentaram os seus filhos ${ }^{(13)}$.

As questões morais das amas de leite estão documentadas em alguns textos pesquisados, nos quais se situam a realidade francesa ${ }^{(13)}$ e a brasileira ${ }^{(16-17)}$. Muitos moralistas acreditavam que por meio do aleitamento materno, passavam atitudes culturais condenáveis aos bebês ${ }^{(13,16-17)}$.

Em um estudo monográfico ${ }^{(18)}$, percebemos uma crítica defensiva frente ao papel das negras, que exerciam o papel de amas de leite no Brasil: "As 'amas negras', não só foram sucumbidas a abdicarem do aleitamento de seus filhos, mas também de sua identidade cultural e étnica, tendo seu caráter rejeitado, levando-as ao ostracismo".

No século XVII generalizou-se o envio das crianças para serem amamentadas por amas, levando a altos índices de mortalidade infantil na França. Para entender a mortalidade infantil, foram resgatados dados estatísticos que verificavam a origem social das crianças cuidadas pelas amas, tendo como variáveis: a profissão dos pais e categorias socioprofissionais. $O$ instinto materno também foi questionado frente a esses índices de mortalidade, porém concluiu-se que outros fatores estavam acima do instinto da vida, tais como valores sociais e econômicos ${ }^{(13)}$.

As mulheres defendiam-se dizendo que não amamentavam por aborrecimento, pois tinham a privação de um suco precioso que seria dado à criança e lhe era necessário para a sua conservação. Ficavam nervosas, sentiam fraqueza na sua constituição física, preocupavam-se com a sua imagem corporal, viam como uma prática de desclassificação social (não nobre), um ato animalesco, era um atentado a sua sexualidade, que restringia o seu prazer sexual ${ }^{(13)}$.

A mulher que amamentava era vista como uma mulher suja, o relacionamento sexual não era bem visto por aqueles que seguiam preceitos morais, pois esses acreditavam que o esperma azedava o leite e podia fazer mal à criança, muitas vezes distanciando o marido da família, e ele ia em busca de sexo fora do casamento ${ }^{(13)}$.

\section{Motivos do desmame}

As razões alegadas pelas mães para o desmame ou introdução de outros alimentos podem ser agrupados por área de responsabilidade: deficiência orgânica da mãe, problema com o bebê, atribuição de responsabilidade à mãe e influência de terceiros, demonstrando que não existem causas isoladas para estabelecer o curso da amamentação, mas, sim, relação 
de fatores associados entre a mãe, o recém-nascido e o contexto em que eles se encontram em uma dada dimensão espaço-temporal ${ }^{(19)}$.

Isto vem corroborar afirmações de que o ato de amamentar tem variado em função do tempo e lugar, obedecendo a determinações sociais e econômicas ${ }^{(14)}$. Essas idéias são compartilhadas ${ }^{(16)}$ baseando-se na afirmação de que o ato de amamentar, além de ser biologicamente determinado, é socioculturalmente condicionado. A determinação sociocultural tende a se sobrepor à determinação biológica, que é tomada, de forma consciente, por um pequeno número de pessoas. Nesse processo, a conscientização é insuficiente para se explicar um comportamento coletivo. Dessa forma, o aleitamento materno ou a recusa raramente é um ato individual e consciente, estando preso à aprovação do seu grupo social ${ }^{(16)}$.

Essa atitude é percebida por meio do levantamento temporal realizado quanto aos motivos que levaram as mulheres ao desmame precoce. Em 1838, na Alemanha, valorizou-se o leite de vaca por ser mais rico em proteína do que o leite humano. Em 1856, descobriu-se o método de produzir leite condensado, um leite que poderia ser conservado e estéril. Já em 1872, verificaram que o leite condensado não auxiliava no desenvolvimento da criança, pois apresentava baixo teor de gordura; nesse mesmo ano, inicia-se orientação alimentar por intermédio de formulações individuais. Em 1883, desenvolveu-se a evaporação do leite de cabra e o estudo da composição do leite humano. No final do século XIX, houve o destaque de firmas americanas por produzirem o substituto do leite materno ${ }^{(15)}$.

\section{À GUISA DE CONCLUSÕES}

Portanto, amamentar deixa de ser instintivo e biológico, para tornar-se "um comportamento social e mutável, conforme as épocas e os costumes"(16).

A amamentação "...é uma escolha individual que desenvolve dentro de um contexto sociocultural, portanto influenciada pela sociedade e pelas condições de vida da mulher"(20).

Comparando as citações acima, conclui-se que a amamentação, seja ela natural/artificial, com uso de mamadeiras e ou amas de leite, foi determinada e condicionada pelo valor social atribuído. Se o aleitamento materno fosse um ato natural, seria imutável nos sujeitos, mesmo com o passar dos tempos.

Várias tecnologias estão sendo desenvolvidas, porém vimos que a preocupação não está em entender o homem, mas, em vez disso, como reage o homem frente a essas novas descobertas. A busca por amas de leite ${ }^{(13)}$, e mesmo a expansão das inúmeras indústrias de leites artificiais ${ }^{(14)}$, que surgiram para atender a uma necessidade social e interesses econômicos dos países desenvolvidos, nos países subdesenvolvidos, influenciaram a criação de novas necessidades e hábitos. Foram descobertas que levaram a altos índices de mortalidade infantil, percebidas como prejuízo ao crescimento populacional de uma nação. Esses questionamentos levaram a indagações e, conseqüentemente, à pesquisa, por meio das quais perceberam e começaram a valorizar o leite materno como o alimento natural e mais completo para o recémnascido.

Ao longo deste século, a mulher vem, de forma gradativa, afastando-se da função de amamentar seus filhos. Principalmente o novo papel da mulher na sociedade, o cuidado com o corpo e a crença de que a amamentação torna as mamas flácidas, a família nuclear constituída de mãe, pai e filho, dificultando a transmissão natural dos costumes antigos, a invenção da mamadeira, a refrigeração e a pasteurização contribuíram para o decréscimo do aleitamento materno e o apogeu do

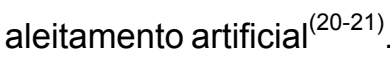

$\mathrm{O}$ ato de amamentar, seja consciente ou inconsciente, é herdado culturalmente e influenciado pela família e pelo meio social em que as pessoas vivem (estímulos culturais, costumes ,crenças e tabus).

No decorrer da história, várias campanhas foram veiculadas pela mídia escrita e falada, devido ao desmame precoce. No fim do século XVIII, aclamou-se pelo amor materno como um valor "natural e social que era favorável à espécie e à sociedade"(13). As crianças eram vistas como riqueza econômica do Estado, a mortalidade infantil era "de $27,5 \%$, de 1.740 a 1.749 , e de $26,5 \%$, de 1.780 a 1.789 "(13). Nessa campanha, empenharam-se profissionais, como médicos, moralistas e administradores, com discursos: econômico conscientizar a mulher da importância dos seres humanos como defesa militar e braços trabalhadores; filosófico idéias de felicidade e igualdade que as mulheres atingiriam com a amamentação, e intermediário - às 
mulheres - 'responsáveis pela nação'. Criou-se aí uma nova imagem de mãe-mulher, a atenção dela deveria estar voltada ao bebê e à criança ${ }^{(13)}$.

No entanto, isso surtiu pouco efeito na promoção do aleitamento materno. A mulher foi enclausurada em seu papel de mãe, sob pena de condenação moral, caso não exercesse adequadamente a sua função. Atualmente, ocorre novamente o deslocamento da responsabilidade, enfoca-se a atenção à criança exercida pelo binômio pai e mãe.

Críticas às campanhas de aleitamento materno são feitas, pois as maiorias são dirigidas às mulheres de classes sociais baixas, devido ao alto índice de mortalidade infantil nessa camada social. A mulher é responsabilizada pelo desconhecimento da técnica da amamentação, desmame precoce e a desnutrição. "As campanhas têm se constituído em estratégia simplificada para reduzir mortalidade infantil em nível de atenção primária"(22).

$$
\text { Percebe-se, então, delegar-se a }
$$
responsabilidade do Estado para a mulher, culpabilizandoa da morbimortalidade infantil.

Apesar dos fatores citados pela Pesquisa Nacional de Saúde e Nutrição (falta de alojamento conjunto em algumas maternidades, à espera pelo início da primeira mamada, baixo peso ao nascer e a prematuridade), somam-se, ainda, fatores socioculturais que também colaboram para o desmame precoce. Para a melhor compreensão dessa temática, devemos contemplar a forma como as nutrizes vêem o aleitamento materno e o desmame ${ }^{(22)}$.

\section{RECOMENDAÇÕES FINAIS}

Acreditamos que o aleitamento materno deve ser vislumbrado além dos aspectos concernentes ao binômio mãe e bebê, pois a visão do homem/pai também é importante. Qual será o sentimento masculino vendo o bebê sugando o seio materno? Como o homem se vê contribuindo para o sucesso do aleitamento materno?

$O$ aleitamento materno não deve ser visto como responsabilidade exclusiva da mulher, percebe-se que a lactante e também nós, profissionais da saúde, temos procurado, frente aos fracassos da amamentação, suporte nas questões biológicas e técnicas ${ }^{(23)}$.

Muitas vezes, os sentimentos e as percepções da nutriz não são valorizados na determinação desse processo, induzindo-a a buscar justificativas que a livrem da responsabilidade de não conseguir amamentar.

Acreditamos que o processo da amamentação deve ser visto sob a óptica da mulher, podendo, dessa forma, compreender o que ela pensa/define sobre si e reconhecer as influências contextuais para podermos, efetivamente, ajudá-la a tomar decisões quer sejam para aleitar ou não ${ }^{(21-24)}$. Isso significa possibilitar e dar "a liberdade de a mulher-mãe explorar e definir sua experiência segundo os significados que isso tenha para ela"(23). Dessa forma, pode-se perceber o aleitamento materno como uma prática complexa e dinâmica, ocupando um contexto "...caracterizado pela interrelação de suas propriedades e dimensões espaço-temporais de sua vida e a vivência de diversos aspectos que dizem respeito à percepção de si como um ser em transformação dentro de um contexto nas relações das esferas familiar, social, cultural, física”(23).

$\mathrm{O}$ ato de amamentar deve ser cultivado de mãe para os filhos, ou seja, culturalmente, dentro de bases sólidas concebidas no seio familiar, social, por meio dos meios de comunicação e do sucesso atingido por outras mulheres que passaram por tal experiência, devendo alicerçar-se em um instrumental teórico e sistematizado de campanhas direcionadas não só à mulher, mas para toda a comunidade, com efetiva participação das mulheres e dos agentes de enfermagem, de outros profissionais assessorados pela mídia, alertando da necessidade de assegurar à puérpera a tranqüilidade de vivenciar o período pós-parto ${ }^{(18,23)}$.

Buscar a óptica do homem nesse processo também é importante, pois ele faz parte do suporte social tão necessário para a manutenção do aleitamento materno.

Podemos inferir que isso só se torna possível quando há conscientização de que a mulher necessita de suporte/apoio social no processo de adaptações ao papel materno, no qual a amamentação está incluída.

Mais do que preconizar o aleitamento materno, a tomada de consciência se faz necessária, ou seja, mulheres/homens que tiverem maiores informações quanto à importância do aleitamento materno terão seus filhos amamentados por mais tempo do que aquelas que não obtiverem essas instruções ${ }^{(25)}$.

O aleitamento materno não deve ser visto como 
uma forma de resolver o problema da desnutrição infantil em população mais carente ${ }^{(3,22)}$. Para isso, há necessidade de se criarem infra-estruturas básicas (educação e saúde).

Uma outra agravante é que a mulher, atualmente, vem exercendo, cada vez mais, o papel de chefe de família. A instabilidade do mercado de trabalho exige disponibilidade da mulher/mãe em seu emprego, competindo com os homens no mercado de trabalho de modelo masculino, porém temos a responsabilidade de orientá-la quanto aos seus direitos de cidadania, quando exerce o seu papel de mãe/nutriz (creche, disponibilidade de horário, local para coleta e conservação do leite materno) e como manter a amamentação, mesmo exercendo atividades extra lar.

Sugerimos que a temática (aleitamento materno) seja implantada no currículo escolar, de forma a tornarse histórica e cultural no contexto educacional dos indivíduos, pois sabemos que o aprendizado se dá, também, pela repetição. A repetição da imagem da mulher amamentando será natural e culturalmente condicionada bem como construída em bancos escolares.

Não encontramos respostas conclusivas quanto ao desmame precoce, mas a história tem nos mostrado que se trata de uma decisão tomada pela mulher, de forma consciente, embora essa conscientização seja negada. Desconstruir valores/significados que estão arraigados é complexo e demorado, porque são valores que hoje não servem ou não são aceitos, mas que fizeram parte da vida de outrora. O resgate histórico é fundamental para compreendermos essa prática.

\section{REFERÊNCIAS BIBLIOGRÁFICAS}

1. Short R. Amamentação, fertilidade e crescimento populacional. IBFAN/UNICEF documento-nossos arquivos [online]. 1998 [acessado 03 jul. 1998]; Disponível em: URL:http:/ / www.elogica.com.br/aleitamento/arquivo/htmI\#INICIO.

2. Ricco RG. Aleitamento natural. In: Woiski JR. Nutrição e dietética em pediatria. $4^{a}$ ed. São Paulo (SP): Atheneu; 1995. p.55-88.

3. Mota AC. Ideologia implícita no discurso da amamentação materna e estudo retrospectivo comparando o crescimento e a mortalidade de lactentes em uso de leite humano e leite de vaca. [dissertação]. Belo Horizonte (MG): Faculdade de Medicina/Universidade Federal de Minas Gerais; 1990.

4. Carvalho MR, Muxi CM. Estamos promovendo a amamentação de maneira eficaz? $5^{\circ}$ Encontro Nacional de Aleitamento Materno; 1997 Setembro 17-20; Londrina; Paraná. Londrina: HURNP; 1997. p.46.

5. Succi RCM. Doenças infecciosas e leite materno. $51^{\circ} \mathrm{Curso}$ Nestlé de Atualização em Pediatria; 1994 Setembro 25-30, Blumenau; Santa Catarina. Blumenau: Sociedade Brasileira de Pediatria; 1994. p.224-5.

6. Pereira OAG. Esquema alimentar. In: Pereira OAG. Alimentação do lactente - normas. $6^{\text {a }}$ ed. Rio de Janeiro (RJ): Cultura Médica; 1982. p. 1-19.

7. Ziegel EE, Cranley MS. Alimentação do recém-nascido. In: Ziegel EE, Cranley MS. Enfermagem obstétrica. Rio de Janeiro(RJ): Guanabara Koogan; 1985. p. 533-69.

8. Whaley LF, Wong DL. O recém-nascido normal. In: Whaley LF, Wong DL. Enfermagem pediátrica - elementos essenciais à intervenção efetiva. Rio de Janeiro (RJ): Guanabara Koogan; 1989. p. 141-2.

9. Organização Mundial de Saúde (OMS). Fatores de saúde que podem interferir na amamentação. In: Organização Mundial de Saúde (OMS). Alimentação infantil. Bases fisiológica. São Paulo (SP): IBFAN Brasil e Instituto de Saúde, OMS, OPAS e UNICEF Brasil; 1994. p. 39-48.
10. Santos EKA. Aleitamento materno. São Paulo. In: Schmitz EM. A Enfermagem em pediatria e puericultura. São Paulo (SP): Atheneu; 1995. p. 25-48.

11. Thompson ED, Ashwill JW. O recém-nascido. In: Thompson ED, Ashwill JW. Uma introdução à enfermagem pediátrica. Porto Alegre (RS): Artes Médicas; 1996. p. 74-5.

12. Ornellas LH. A alimentação na idade média. In: Ornellas LH. A alimentação através dos tempos. Rio de Janeiro (RJ): FENAME; 1978. p.9-49.

13. Badinter E. Um amor conquistado - o mito do amor materno. $5^{\mathrm{a}}$ ed. Rio de Janeiro (RJ): Nova Fronteira; 1985.

14. Vinha VHP, Scochi CGS. Aleitamento materno evolução histórica. Femina 1989 outubro; 17(10):819-23.

15. Rea MF. Substitutos do leite materno: passado e presente. Rev.Saúde Pública 1990; 24(3):241-9.

16. Silva AAM. Amamentação: fardo ou desejo? Estudo histórico social dos deveres e práticas sobre aleitamento na sociedade brasileira. [dissertação]. Ribeirão Preto (SP): Faculdade de Medicina de Ribeirão Preto/USP; 1990.

17. Costa JF. Adultos e crianças. In: Costa JF. Ordem médica e norma familiar. $3^{a}$ ed. Rio de Janeiro (RJ): Graal; 1989. p.153214.

18. Correia M. Importância do alojamento conjunto no sucesso do aleitamento materno. [monografia]. Ribeirão Preto (SP): Departamento de Enfermagem/União das Faculdades Barão de Mauá; 1997.

19. Rea MF, Cukier R. Razões de desmame e de introdução da mamadeira: uma abordagem alternativa para seu estudo. Rev. Saúde Pública 1988; 22(3):184-91.

20. Bitar MAF. Aleitamento materno: um estudo etnográfico sobre os costumes crenças e tabus ligados a esta prática. [dissertação]. Belém (PA): Centro de Ciências da Saúde Departamento de Enfermagem/Universidade Federal do Pará; 1995.

21. Nakano AMS. O Aleitamento materno no cotidiano feminino. [doutorado]. Ribeirão Preto (SP): Escola de Enfermagem de Ribeirão Preto/USP; 1996. 
22. Javorski M. Os significados do aleitamento materno para mães de prematuros em cuidado canguru. [dissertação]. Ribeirão Preto (SP): Escola de Enfermagem de Ribeirão Preto/ USP; 1997.

23. Silva IA. Amamentar: uma questão de assumir riscos ou garantir benefícios. [dissertação]. São Paulo (SP): Escola de Enfermagem/USP; 1994.

24. Arantes CIS. O fenômeno amamentação: uma proposta compreensiva. [dissertação]. Ribeirão Preto (SP): Escola de Enfermagem de Ribeirão Preto/USP; 1991.

25. Bouer J. Nível social determina hábito. Folha de São Paulo [online] 1996 [ acessado 11 Ag. 1996]; Disponível em: URL:http:/ /www.uol.com.br/saude/noticiar/s110896g.htm. 